\title{
Breakfast Skipping and Obesity Risk among Urban Adults in Bangladesh
}

\author{
Shatabdi Goon ${ }^{1}$, Md.Saiful Islam² \\ ${ }^{1}$ Departement of Nutrition and Food Engineering, Daffodil International University, Dhaka, Bangladesh \\ ${ }^{2}$ Departement of Applied Dietitics and Food Technology, Kushtia Islamic Univeristy
}

\begin{tabular}{l}
\hline \hline Article Info \\
\hline Article history: \\
Received Jan 21, 2014 \\
Revised Feb 11, 2014 \\
Accepted Feb 28, 2014 \\
\hline
\end{tabular}

Keyword:

Breakfast

Healthy lifestyle

Breakfast skipping

Health status

Obesity risk

Urban adult

\begin{abstract}
Positive association between skipping breakfast and overweight and obesity is globally observed regardless of cultural diversity among countries. A cross-sectional descriptive study was performed on a total of 426 urban adults, who were randomly selected in a nutrition counseling center of Dhaka city, Bangladesh. The objective of this study was determining the association between breakfast skipping and obesity risk in urban adults of Bangladesh. Results indicated that approximately $35.2 \%$ of the sample skipped breakfast. Gender was the only statistically significant sociodemographic variable, with females skipping at two times the rate of males (OR 95\% CI: 1.9; 1.3-2.9). Obesity was detected among $39.5 \%$ of breakfast skippers and they showed significantly high prevalence $\left(X^{2}=30.15, p<0.05\right)$. Skippers were significantly more likely being obese (OR 3.5; 95\% CI 2.2-5.5) and obesity was more prevalent in female skippers $\left(\mathrm{X}^{2}=8.7\right.$, $p<0.05$ ), with three times more compared to male skippers (OR 95\% CI: 2.8; 1.4-5.9). Breakfast skipping is highly prevalent among urban adult population with significant association of obesity in Bangladesh. Health promotion strategies should be used to encourage all adults to eat breakfast regularly.
\end{abstract}

Copyright (C) 2014 Institute of Advanced Engineering and Science. All rights reserved.

\section{Corresponding Author:}

Shatabdi Goon,

Departement of Nutrition and Food Engineering,

Daffodil International University,

Dhaka, Bangladesh.

Email: shatabdigoon@yahoo.com

\section{INTRODUCTION}

Breakfast consumption has been identified as an important factor in the nutritional well-being of adult [1]-[3]. Some studies reported that breakfast could play an important role in the prevention of adult chronic diseases such as heart disease, cancer, diabetes, and osteoporosis [4]. Breakfast provides a significant proportion of the day's total nutrient intake [5]-[7] with lower intakes of fat and higher intakes of carbohydrate [8],[9], dietary fibre and certain micronutrients [10],[11]. Regular breakfast consumption is associated with better diets for adults overall where skipping is associated with a lower diet quality and concentrated energy intakes [12] meeting two thirds of the Recommended Dietary Allowance for vitamins and minerals [13] and health-compromising behaviors in adults such as smoking, infrequent exercise, low education level, higher BMI [14]. Breakfast skipping is highly prevalent in the United States and Europe (10\% to 30\%) [15]. Skipping breakfast is a fairly common practice with $23 \%$ of adults and there is evidence that skipping breakfast is becoming more common in developing countries also. According to a recent survey from Food Insight, 93\% of Americans agree that breakfast is the most important meal, yet fewer than half 
(44\%) are eating it every day. The 2002 National Health and Nutrition Examination Survey (NHANES) suggests that American adults frequently skip breakfast (18\%) [16] where 12-34\% of youth regularly skip breakfast worldwide [17]-[24]. Adults who consumed breakfast regularly have significantly lower fat and cholesterol intakes [17] and healthy body weight [18] than those who skip breakfast. Regular consumption of a breakfast meal may reduce the risk of obesity and other chronic diseases [25]-[26]. Eating breakfast help to reduce dietary fat and minimize impulsive snacking promoting a preventive measure in obesity [27]. Breakfast skipping increased during the transition to adulthood, and both dietary behaviors are associated with increased weight gain from adolescence to adulthood [28]. Eating breakfast is associated with significantly lower body mass index compared to skipping breakfast [29]-[31]. Most cross-sectional studies that have examined the association between breakfast habits and measures of obesity in adults report an inverse association, even with adjustment for potential confounding factors [32]-[36],[38]. In a population based survey, it was found that the unadjusted odds ratio of obesity in breakfast skippers was two times more than non skippers (95\% CI: 1.23 ; 1.06-1.43) [37]. Study showed that skipping breakfast was associated with increased prevalence of obesity (odds ratio $=4.5,95 \%$ confidence interval: $1.57,12.90$ ) [39]. Prospective studies also examined the associations between breakfast habits and body weight [40]-[42]. In one study, promoting breakfast eating was associated with a $45 \%$ reduced risk for obesity [odds ratio $=0.55(95 \% \mathrm{CI}=$ $0.33,0.91$ )] in adults [39], whereas skipping breakfast appeared to be associated with a significant increase in risk of developing obesity [43]. Among male health professionals, inverse associations were observed between breakfast cereal intake and BMI and between breakfast cereal intake and weight gain [44]. Breakfast frequency and quality may contribute to appetite regulation, quality of diet, and prevention of obesity and chronic disease through a variety of mechanisms [45]. Many studies have reported that ready-to-eat breakfast cereal [46] and other fiber-rich foods [47]-[50] are associated with lower risk of obesity [51]-[54]. Intake of fiber-rich breakfast foods may improve blood sugar control and possibly prevent excess eating throughout the day promoting weight management [55]-[59].

Breakfast consumption is related to satiety and reduced risk of obesity, type 2 diabetes and possibly of cardiovascular disease and cancer. Breakfast is considered the most important meal of the day for various reasons, but most of the adult used to skip their breakfast possessing detrimental health sequel. This is first documented study in Bangladesh to determine the prevalence of breakfast skipping in urban adults with significant association of obesity.

\section{RESEARCH METHOD}

A cross-sectional descriptive study design was carried out from April to May, 2013 among urban adults attending in a nutrition counseling center located at Dhaka, Bangladesh. A total number of 426 adults were randomly selected from the center registered for their regular visit. Adults having medical conditions were excluded from the study and adults with normal conditions were included in the study. Equal number of male and female participants was selected for the interview. All of the selected participants were made well informed of the study aims and informed written consent was obtained from the subjects. Interviews were conducted in the counseling room. A semi-structured questionnaire was used to collect data regarding their age, sex, education, weight, height, BMI level, meal pattern, eating pattern of breakfast, skipping of breakfast, reason behind skipping of breakfast, presence of health problems etc. Sample completed the questionnaire anonymously and used about 30 minutes to complete the scale. They could decline to participate in the project at any time while completing the questionnaire.

\section{Measures \\ Data were collected by a self-administered questionnaire. The questionnaire was composed as follows:}

Demographic characteristics were age, sex and educational level.

Weight status was determined by Body Mass Index (BMI). The height and weight were measured by selfreport and the BMI was calculated by the standard formula: weight $(\mathrm{kg})$ divided by height $\left(\mathrm{m}^{2}\right)$. BMI was plotted on the age and sex-specific cutoff points to define the different body sizes of respondents according to nationally accepted guidelines. A BMI greater than or equal to 25 is overweight and a BMI greater than or equal to 30 is obesity. Ranges from 18.5 to 24.9 of BMI ensure the normal level.

\section{Statistical analysis}

Crude odds ratios (OR) was calculated to evaluate the risk of independent variables and associated $95 \%$ confidence intervals. The risk (odds ratio and chi square) of obesity and associated 95 percent 
confidence intervals was estimated using simple logistic regression analysis. Multivariable logistic regression modeling was used to control all risk estimates for covariates. Possible covariates, participants' healthpromoting behaviors and demographic characteristics, were evaluated as potential confounders of the relationship between eating patterns of breakfast and obesity status. All statistical analyses were performed using SPSS for Windows Version 15.0, with a significance level of $\mathrm{P}<0.05$.

\section{RESULTS AND ANALYSIS}

A total number of 152(35.8\%) respondents reported to skip their breakfast at regular basis. Female respondents (60.5\%) skipped breakfast more compared to their male respondents (39.5\%), with females skipping at two times the rate of males (OR 95\% CI: 1.9; 0.90-4.13). Sample skipped their breakfast having different reasons. The main reasons for breakfast skipping were: habit (39.4\%), work pressure (23.2\%), lack of time (16.2\%), away from family (14\%), unable to prepare $(7.7 \%)$ (Table 1$)$.

Unadjusted odd ratio for breakfast skipper having obesity risk was established in this study. Table 2 Skippers were significantly more likely to be obese (OR 3.5; 95\% CI 2.2-5.5). Obesity was detected among $39.5 \%$ of breakfast skippers and they showed significantly high prevalence $\left(\mathrm{X}^{2}=30.15, p<0.05\right)$. [Table 3] Obesity was more prevalent in female skippers $\left(\mathrm{X}^{2}=8.7, p<0.05\right)$, with three times more obese than male skippers (OR 95\% CI: 2.8; 1.4-5.9). [Table 4] Intensity of the correlation between Breakfast skipping and obesity was found significantly in Table 5 . In this study, statistically highly significant correlation $(P=0.01)$ between Breakfast skipping and obesity were established.

Table 1: Characteristics and eating pattern of breakfast among respondents

\begin{tabular}{cc}
\hline Age & Respondents (\%) \\
\hline $20-30$ & $95(22.3 \%)$ \\
$31-40$ & $116(27.2 \%)$ \\
$41-50$ & $141(33 \%)$ \\
$51-60$ & $74(17.5 \%)$ \\
\hline Sex & Respondents (\%) \\
\hline Male & $213(50 \%)$ \\
Female & $213(50 \%)$ \\
\hline Weight status(BMI Level) & Respondents (\%) \\
\hline Underweight & $7(1.6 \%)$ \\
Normal weight & $192(45 \%)$ \\
Overweight & $124(29.2 \%)$ \\
Obesity & $103(24.1 \%)$ \\
\hline Obesity by sex & Respondents (\%) \\
\hline Male & $42(41.4 \%)$ \\
Female & $61(58.6 \%)$ \\
\hline Breakfast skipping & Respondents (\%) \\
\hline Yes & $152(35.8 \%)$ \\
No & $274(64.2 \%)$ \\
\hline Breakfast skipping by sex & Respondents (\%) \\
\hline Male skipper & $60(39.5 \%)$ \\
Female skipper & $92(60.5 \%)$ \\
\hline Reason of skipping & Respondents (\%) \\
\hline Work pressure & $98(23 \%)$ \\
Habit & $168(39.4 \%)$ \\
Awable to prepare from family & $31(7.2 \%)$ \\
Lack of time & $60(14 \%)$ \\
\hline
\end{tabular}

Table 2: Unadjusted ORs for breakfast skipper by obesity risk

\begin{tabular}{llc}
\hline & Risk of obesity & \\
\hline $\begin{array}{c}\text { Breakfast } \\
\text { skipper }\end{array}$ & $\mathrm{n}$ & $\mathrm{OR}(95 \% \mathrm{CI})$ \\
& & $3.5,2.2-5.5$ \\
\end{tabular}

Table 3: Distribution of breakfast skippers according to the presence or absence of obesity

\begin{tabular}{ccccc}
\hline Character & Present/absent & Obesity & Statistical values & $\begin{array}{c}\text { ORs } \\
(\mathbf{9 5 \%} \text { CI) }\end{array}$ \\
\hline Breakfast skipper & Present & $60(39.5 \%)$ & $\mathrm{X}^{2}=30.15, \mathrm{p}<0.05$ & $3.5,2.2-5.5$ \\
& Absent & $43(15.7 \%)$ & & \\
\hline
\end{tabular}




\begin{tabular}{|c|c|c|c|c|}
\hline Character & Present/absent & Obesity & Statistical values & $\begin{array}{c}\text { ORs } \\
(95 \% \mathrm{CI})\end{array}$ \\
\hline
\end{tabular}

Table 5: Data of correlation strength between breakfast skipping and obesity

\begin{tabular}{lcc}
\hline Variables & Breakfast skipping & Obesity \\
\hline Breakfast skipping & 1 & $.572^{* *}$ \\
& & 0.00 \\
$\mathbf{N}$ & 426 & 426 \\
Obesity & $.572^{* *}$ & 1 \\
& & \\
$\mathbf{N}$ & 0.00 & 426 \\
\hline & 426 &
\end{tabular}

\section{Discussion}

Breakfast contributes to the quality and quantity of a person's daily dietary intake [5]-[9], and breakfast-skipping has been linked to inadequate dietary nutrition [12],[13] with several health problems. The results of the current study support the hypothesis that breakfast skipping is more prevalent among urban adult population of Bangladesh with significant association of specific health problems such as obesity and overweight. The overall prevalence of breakfast skipping was estimated as $35.2 \%$ among Bangladeshi adult population. A number of studies have looked at the prevalence of skipping breakfast. Several studies showed that the prevalence of breakfast skipping, among Louisiana (France) adult was higher than in other countries. A Cross-sectional survey Nicklas TA, et. al (1998) of young adults in Bogalusa, La showed the prevalence of breakfast skipping with 37\% [60] where Nicklas et al. and Shaw [61] reported that 19\% of American and $12 \%$ of Australian young people skipped breakfast. In this study the prevalence of breakfast skipping among adult population of Bangladesh is also in high with $35.2 \%$ which was close to the result of the study on France adults ${ }^{60}$. Another study Deshmukh-Taskar PR, et. Al (2010) showed the prevalence of breakfast skipping among adolescents with 31.5\% where present result reports the prevalence with 35.2\% [62]. Another study showed the prevalence of breakfast skipping with $22 \%$ where a high prevalence was also observed in this study [36].

The sociodemographic characteristics of breakfast skippers have also been investigated. Female respondents (60.5\%) skipped breakfast more (OR 95\% CI: 1.9; 0.90-4.13) compared to their male respondents (39.5\%) in this study. Similarly, another study Shaw, Mary E. (1998) showed that female respondents skipped breakfast more compared to their male respondents [61]. But a contradictory result was found in a cross-sectional survey conducted among medical students in the Inner Mongolia Medical College showed the prevalence of skipping breakfast with $41.7 \%$ and $23.5 \%$ for males and females, respectively [63].

In this study it was reported by skippers that the main reasons for skipping were: habit (39.5\%), work pressure (23.2\%), lack of time (16.2\%), away from family (14\%), unable to prepare (7.7\%). Similarly, Singleton and Rhoads (1982) ${ }^{74}$ found that the most common reasons given for skipping were no time (43\%) and not being hungry or habit of skipping (42\%); less common reasons included being on a diet to lose weight, not feeling good, no one to prepare food, not liking the food served, and food not being available. Lack of time and habit privilege the reason behind breakfast skipping most often.

Regular consumption of a breakfast meal may reduce the risk of obesity and other chronic diseases [24]-[26]. In this study obesity risk (OR 3.5; 95\% CI 2.2-5.5) was significantly associated with breakfast skipping. Several other studies including Stockman et al. and Berkey et al. have yielded similar results, showing that inconsistent or irregular breakfast eating was significantly associated with being overweight [64],[65]. In one study, increased meal frequency (meals per week) was associated with a $45 \%$ reduced risk for obesity [odds ratio $=0.55(95 \% \mathrm{CI}=0.33,0.91)$ ] in adults [39], whereas skipping breakfast appeared to be associated with a significant increase in risk of developing obesity [43]. In a study Huang CJ,et. al (2010), the unadjusted odds ratio of obesity in breakfast skippers was 1.23 (95\% CI: 1.06, 1.43) where in this study the unadjusted odds ratio of obesity in breakfast skippers was 3.5 (95\% CI :2.2-5.5) which was thrice in the sense [37]. Another study Ma Y, et. al (2003) showed that skipping breakfast was associated with increased prevalence of obesity (odds ratio $=4.5,95 \%$ confidence interval: $1.57,12.90$ ), where this study also showed a high prevalence (OR 3.5; 95\% CI 2.2- 5.5) [39].

We suggested that regular breakfast eating was a useful predictor for adult health-promoting behaviors. Our study revealed that health-promoting behaviors differ between the regular breakfast eater and 
breakfast skipper groups. In other words, the breakfast eaters had a higher frequency of health promoting behaviors, such as feeling of energetic in their work, having more stress management skills, less tendency to eat unhealthy snacks in midmorning and possessing of less health problems. Niemeier HM et_al showed that fast food consumption and breakfast skipping increased parallel in recent years where this study also suggests that fast food consumption was two times (OR 2.5; 95\% CI 1.13 - 5.5) higher in breakfast skippers compared to non-skippers leading obesity [66].

The results of this study may be an indication that the high prevalence of breakfast skipping among urban adults in Bangladesh can be threatening considering its detrimental health effects. Several studies showed that skipping breakfast may put people on the fast track to weight gain, heart disease, osteoporosis, irritability or mood swings, menstrual irregularity, low energy levels, low memory and hormonal stress. This study also reports that breakfast skipping is in high among adult in Bangladesh and skippers were found to be associated with obesity.

This study only evaluated the prevalence of breakfast skipping and some of its associated health effects in Bangladeshi adults. Unless evaluating the all possible effect of breakfast skipping in both the short and long term health of adult professionals, it will not be able to determine the overall risk associated with breakfast skipping. Considering this issue, the next step of this study will be to follow up respondents for a period of time to evaluate the adverse health outcome associated with breakfast skipping.

The study has several limitations and this influence the generalizability of the findings. First, since the data were collected through a self-reporting measure, it is possible that the findings were affected by a social desirability response set and the study is cross-sectional which does not infer causal relationships Second, breakfast eating was only counted from Monday to Friday; seven-day measurements or in-depth interviews might increase the reliability and validity of our understanding of this phenomenon. Third, we did not explore the content or quality of breakfast. Furthermore, we examined only one nutrition counseling center located in Dhaka, Bangladesh, caution should be taken to generalize the data for other location outside Dhaka city.

\section{CONCLUSION}

Regular breakfast intake is strongly associated with reduced risk of a spectrum of metabolic conditions such as obesity, diabetes, cardiovascular disease etc. This study provides evidence of increasing trend of breakfast skipping in adults of Bangladesh where skipping correlates with being associated to different health problems, obesity, low energy level and with less health-promoting behavior. Considering such a high prevalence of breakfast skipping with associated adverse health outcome in urban population of Bangladesh, these findings can provide baseline data for taking the initiative to monitor and make people aware regarding the importance of breakfast eating.

\section{REFERENCES}

[1] Szajewska H, Ruszczynski M. "Systematic review demonstrating that breakfast consumption influences body weight outcomes in children and adolescents in Europe”, Crit Rev Food Sci Nutr. Vol/Issue: 50(2). Pp. 113-9, 2010. doi: $10.1080 / 10408390903467514$.

[2] Nicklas TA, O’Neil C, Myers L. “The Importance of Breakfast Consumption to Nutrition of Children, Adolescents, and Young Adults”, Nutr Today. Vol/Issue: 39(1). Pp. 30-39, 2004.

[3] Mekary RA, Giovannucci E, Willett WC, van Dam RM, Hu FB. "Eating patterns and type 2 diabetes risk in men: breakfast omission, eating frequency, and snacking”, Am J Clin Nutr. Vol/Issue: 95(5). Pp. 1182-9, 2012. doi: 10.3945/ajcn.111.028209. Epub 2012 Mar 28.

[4] Sandercock GRH, Voss C, Dye L. "Associations between habitual school-day breakfast consumption, body mass index, physical activity and cardiorespiratory fitness in English schoolchildren”, Eur J Clin Nutr, Vol. 64. Pp. 10861092, 2010.

[5] Affenito SG, Thompson DR, Barton BA, Franko DL, Daniels SR, Obarzanek E, Schreiber GB, Striegel-Moore RH. "Breakfast consumption by African-American and white adolescent girls correlates positively with calcium and fiber intake and negatively with body mass index”, J Am Diet Assoc. Vol/Issue: 105(6). Pp. 938-45, 2005.

[6] Albertson AM, Thompson D, Franko DL, Kleinman RE, Barton BA, Crockett SJ. "Consumption of breakfast cereal is associated with positive health outcomes: evidence from the National Heart, Lung, and Blood Institute Growth and Health Study”, Nutr Res. Vol/Issue: 28(11). Pp. 744-52, 2008. doi: 10.1016/j.nutres.2008.09.002.

[7] Ruxton $\mathrm{CH}$, Kirk TR. "Breakfast: a review of associations with measures of dietary intake, physiology and biochemistry”, Br J Nutr. Vol/Issue: 78(2). Pp. 199-213, 1997.

[8] van den Boom A, Serra-Majem L, Ribas L, Ngo J, Pérez-Rodrigo C, Aranceta J, Fletcher R "The contribution of ready-to-eat cereals to daily nutrient intake and breakfast quality in a Mediterranean setting”, $J$ Am Coll Nutr. Vol/Issue: 25(2). Pp. 135-43, 2006.

[9] Morgan KJ, Zabik ME. "The influence of ready-to-eat cereal consumption at breakfast on nutrient intakes of individuals 62 years and older”, J Am Coll Nutr. Vol/Issue: 3(1). Pp. 27-44, 1984. 
[10] Williams P. "Breakfast and the diets of Australian adults: an analysis of data from the 1995 National Nutrition Survey”, Int J Food Sci Nutr. Vol/Issue: 56(1). Pp. 65-79, 2005.

[11] Song WO, Chun OK, Obayashi S, Cho S, Chung CE. "Is consumption of breakfast associated with body mass index in US adults?”, J Am Diet Assoc. Vol. 105. Pp. 1373-82, 2005.

[12] Morgan KJ, Zabik ME, Stampley GL. "The role of breakfast in diet adequacy of the U.S. adult population”, $J A m$ Coll Nutr. Vol. 5. Pp. 551-63, 1986.

[13] Mekary RA, Giovannucci E, Cahill L, Willett WC, van Dam RM, Hu FB. "Eating patterns and type 2 diabetes risk in older women: breakfast consumption and eating frequency”, Am J Clin Nutr. Vol/Issue: 98(2). Pp. 436-43, 2013. doi: 10.3945/ajcn.112.057521. Epub 2013 Jun 12.

[14] A Keski-Rahkonen ${ }^{1,2}$, J Kaprio ${ }^{1,3}$, A Rissanen ${ }^{2}$, M Virkkunen ${ }^{2}$ and R J Rose ${ }^{4}$. "Breakfast skipping and healthcompromising behaviors in adolescents and adults”, E J Clin Nutr, Vol. 57. Pp. 842-853, 2003. doi:10.1038/sj.ejcn.1601618

[15] Gail C. Rampersaud, Mark A. Pereira, Beverly L. Girard, Judi Adams, Jordan D. Metzl. "Breakfast Habits, Nutritional Status, Body Weight, and Academic Performance in Children and Adolescents”, J Am Diet Assoc, Vol/Issue: 105(5). Pp. 743-760, 2005.

[16] Kant AK, Graubard BI. Secular trends in patterns of self-reported food consumption of adult Americans: NHANES 19.

[17] Stanton JL Jr., Keast DR. "Serum cholesterol, fat intake, and breakfast consumption in the United States adult population”, J Am Coll Nutr. Vol. 8. Pp. 567-72, 1989.

[18] Dubois L, Girard M, Potvin Kent M, Farmer A, Tatone-Tokuda F. "Breakfast skipping is associated with differences in meal patterns, macronutrient intakes and overweight among pre-school children”, Public Health Nutr. Vol/Issue: 12(1). Pp. 19-28, 2009. doi: 10.1017/S1368980008001894. Epub 2008 Mar 18.

[19] Skinner JD, Salvetti NN, Ezell JM, Penfield MP, Costello CA. “Appalachian adolescents' eating patterns and nutrient intakes”, J Am Diet Assoc. Vol. 85. Pp. 1093-9, 1985.

[20] Sampson AE, Dixit S, Meyers AF, Houser RJ. "The nutritional impact of breakfast consumption on the diets of inner-city African-American elementary school children”, J Natl Med Assoc. Vol. 87. Pp. 195-202, 1995.

[21] Nicklas TA, Bao W, Webber LS, Berenson GS. "Breakfast consumption affects adequacy of total daily intake in children”, J Am Diet Assoc. Vol. 93. Pp. 886-91, 1993.

[22] Nicklas TA, Reger C, Myers L, O'Neil C. "Breakfast consumption with and without vitamin-mineral supplement use favorably impacts daily nutrient intake of ninth-grade students”, J Adolesc Health. Vol. 27. Pp. 314-21, 2000.

[23] Graham MV, Uphold CR. "Health perceptions and behaviors of school-age boys and girls", J Community Health Nurs. Vol. 9. Pp. 77-8, 1992.

[24] Siega-Riz AM, Popkin BM, Carson T. "Trends in breakfast consumption for children in the United States from 1965-1991”, Am J Clin Nutr. Vol. 67. Pp. S748-56, 1998.

[25] Keim NL, Van Loan MD, Horn WF, Barbieri TF, Mayclin PL. "Weight loss is greater with consumption of large morning meals and fat-free mass is preserved with large evening meals in women on a controlled weight reduction regimen”, J Nutr. Vol. 127. Pp. 75-82, 1997.

[26] Kleemola P, Puska P, Vartiainen E, Roos E, Luoto R, Ehnholm C. "The effect of breakfast cereal on diet and serum cholesterol: a randomized trial in North Karelia, Finland”, Eur J Clin Nutr. Vol. 53. Pp. 716-21, 1999.

[27] Schlundt DG, Hill JO, Sbrocco T, Pope-Cordle J, Sharp T. "The role of breakfast in the treatment of obesity: a randomized clinical trial”, Am J Clin Nutr. Vol. 55. Pp. 645-51, 1992.

[28] Heather M. Niemeier, Hollie A. Raynor, Elizabeth E. Lloyd-Richardson, Michelle L. Rogers,Rena R. Wing. "Fast Food Consumption and Breakfast Skipping: Predictors of Weight Gain from Adolescence to Adulthood in a Nationally Representative Sample”, J Adol heal, Vol/Issue: 39(6). Pp. 842-849, 2006.

[29] Sungsoo Cho, PhD, Marion Dietrich, PhD, Coralie J.P. Brown, MPH, Celeste A. Clark, MS, and Gladys Block, $\mathrm{PhD}$. "The Effect of Breakfast Type on Total Daily EnergyIntake and Body Mass Index: Results from the ThirdNational Health and Nutrition Examination Survey (NHANES III)”, J Am Coll Nutr, Vol/Issue: 22(4). Pp. 296302, 2003.

[30] Song WO, Chun OK, Obayashi S, Cho S, Chung CE. "Is consumption of breakfast associated with body mass index in US adults?” J Am Diet Assoc. Vol/Issue: 105(9). Pp. 1373-82, 2005.

[31] Horikawa C, Kodama S, Yachi Y, Heianza Y, Hirasawa R, Ibe Y, Saito K, Shimano H, Yamada N, Sone H. "Skipping breakfast and prevalence of overweight and obesity in Asian and Pacific regions: a meta-analysis", Prev Med. Vol/Issue: 53(4-5). Pp. 260-7, 2011. doi: 10.1016/j.ypmed.2011.08.030. Epub 2011 Aug 27.

[32] Thompson-McCormick JJ, Thomas JJ, Bainivualiku A, Khan AN, Becker AE. "Breakfast skipping as a risk correlate of overweight and obesity in school-going ethnic Fijian adolescent girls”, Asia Pac J Clin Nutr. Vol/Issue: 19(3). Pp. 372-82, 2010.

[33] Katharine E. Alexander, ${ }^{1}$ Emily E. Ventura, ${ }^{1}$ Donna Spruijt-Metz, ${ }^{1}$ Marc J. Weigensberg, ${ }^{1,2}$ Michael I. Goran, ${ }^{1,3}$ and Jaimie N. Davis". "Association of Breakfast Skipping With Visceral Fat and Insulin Indices in Overweight Latino Youth. Obesity (Silver Spring)”, Vol/Issue: 17(8). Pp. 1528-1533, 2009.

[34] Summerbell CD, Moody RC, Shanks J, Stock MJ, Geissler C. "Relationship between feeding pattern and body mass index in 220 free-living people in four age groups”, Eur J Clin Nutr. Vol. 50. Pp. 513-9, 1996.

[35] Wyatt HR, Grunwald GK, Mosca CL, Klem ML,Wing RR, Hill JO. "Long-term weight loss and breakfast in subjects in the National Weight Control Registry”, Obes Res. Vol. 10. Pp. 78-82, 2002. 
[36] Lisa R. Purslow,Manjinder S. SandhuNita Forouhi, Elizabeth H. Young,Robert N. Luben3, Ailsa A. Welch3, et_al. "Energy Intake at Breakfast and Weight Change: Prospective Study of 6,764 Middle-aged Men and Women”, Am. J. Epidemiol. Vol/Issue: 167(2). Pp. 188-192, 2008. doi: 10.1093/aje/kwm309

[37] Huang CJ, Hu HT, Fan YC, Liao YM, Tsai PS. “Associations of breakfast skipping with obesity and health-related quality of life: evidence from a national survey in Taiwan”, Int J Obes (Lond). Vol/Issue: 34(4). Pp. 720-5, 2010. doi: 10.1038/ijo.2009.285. Epub 2010 Jan 12.

[38] Timlin MT, Pereira MA, Story M, Neumark-Sztainer D. "Breakfast eating and weight change in a 5-year prospective analysis of adolescents: Project EAT (Eating Among Teens)”, Pediatrics. Vol/Issue: 121(3). Pp. e63845, 2008. doi: 10.1542/peds.2007-1035.

[39] Ma Y, Bertone ER, Stanek EJ, Reed GW, Hebert JR, Cohen NL,et_al. “Association between eating patterns and obesity in a free-living US adult population”, Am J Epidemiol. Vol. 158. Pp. 85-92, 2003.

[40] Maskarinec G, Novotny R, Tasaki K. "Dietary patterns are associated with body mass index in multiethnic women”, J Nutr. Vol. 130. Pp. 3068-72, 2000.

[41] van der Heijden AA, Hu FB, Rimm EB, van Dam RM. "A prospective study of breakfast consumption and weight gain among U.S. men”, Obesity (Silver Spring). Vol. 15. Pp. 2463-2469, 2007.

[42] Lisa R. Purslow,Manjinder S. Sandhu,Nita Forouhi, Elizabeth H. Young,Robert N. Luben, Ailsa A. Welch,et_al. “Energy Intake at Breakfast and Weight Change: Prospective Study of 6,764 Middle-aged Men and Women”, Am. J. Epidemiol. Vol/Issue: 167(2). Pp. 188-192, 2008. doi: 10.1093/aje/kwm309.

[43] Cho S, Dietrich M, Brown CJ, Clark CA, Block G. "The effect of breakfast type on total daily energy intake and body mass index: results from the Third National Health and Nutrition Examination Survey (NHANES III)”, $J$ Am Coll Nutr. Vol/Issue: 22(4). Pp. 296-302, 2003.

[44] Bazzano LA, Song Y, Bubes V, Good CK, Manson JE, Liu S. "Dietary intake of whole and refined grain breakfast cereals and weight gain in men”, Obes Res. Vol/Issue: 13(11). Pp. 1952-60, 2005.

[45] Timlin MT, Pereira MA. "Breakfast frequency and quality in the etiology of adult obesity and chronic diseases", Nutr Rev. Vol. 65. Pp. 268-81, 2007.

[46] Cho S, Dietrich M, Brown CJ, Clark CA, Block G. "The effect of breakfast type on total daily energy intake and body mass index: results from the Third National Health and Nutrition Examination Survey (NHANES III)", J Am Coll Nutr. Vol/Issue: 22(4). Pp. 296-302, 2003.

[47] Maskarinec G, Novotny R, Tasaki K. "Dietary patterns are associated with body mass index in multiethnic women”, J Nutr. Vol. 130. Pp. 3068-72, 2000.

[48] Koh-Banerjee P, Wang Y, Hu FB, Spiegelman D, Willett WC, Rimm EB. "Changes in body weight and body fat distribution as risk factors for clinical diabetes in US men”, Am J Epidemiol. Vol. 159. Pp. 1150-9, 2004.

[49] McKeown NM, Meigs JB, Liu S, Wilson PW, Jacques PF. "Whole-grain intake is favorably associated with metabolic risk factors for type 2 diabetes and cardiovascular disease in the Framingham Offspring Study", Am J Clin Nutr. Vol. 76. Pp. 390-8, 2002.

[50] Pereira MA, Jacobs DJ, Pins JJ, Marquart L, Keenan J. Whole grains, cereal fiber, and chronic disease: the epidemiologic evidence. In: Spiller GA, editor. CRC Handbook of dietary fiber in human disease. 3rd ed. New York: CRC Press. Pp. 481-98, 2001.

[51] Cho S, Dietrich M, Brown CJ, Clark CA, Block G. "The effect of breakfast type on total daily energy intake and body mass index: results from the Third National Health and Nutrition Examination Survey (NHANES III)", $J$ Am Coll Nutr. Vol/Issue: 22(4). Pp. 296-302, 2003.

[52] Liljeberg HG, Akerberg AK, Bjorck IM. "Effect of the glycemic index and content of indigestible carbohydrates of cereal-based breakfast meals on glucose tolerance at lunch in healthy subjects”, Am J Clin Nutr. Vol. 69. Pp. 64755, 1999.

[53] Bellisle F, McDevitt R, Prentice AM. "Meal frequency and energy balance”, Br J Nutr. Vol. 77 Suppl 1. Pp. S5770, 1997.

[54] Liljeberg HG, Akerberg AK, Bjorck IM. "Effect of the glycemic index and content of indigestible carbohydrates of cereal-based breakfast meals on glucose tolerance at lunch in healthy subjects”, Am J Clin Nutr. Vol. 69. Pp. 64755, 1999.

[55] Nestler JE, Barlascini CO, Clore JN, Blackard WG. "Absorption characteristic of breakfast determines insulin sensitivity and carbohydrate tolerance for lunch”, Diabetes Care. Vol. 11. Pp. 755-60, 1988.

[56] Clark CA, Gardiner J, McBurney MI, Anderson S, Weatherspoon LJ, Henry DN, Hord NG. "Effects of breakfast meal composition on second meal metabolic responses in adults with type 2 diabetes mellitus", Eur J Clin Nutr. Vol. 60. Pp. 1122-9, 2006.

[57] Mark A. Pereira ${ }^{5}$,Elizabeth Erickson ${ }^{5}$, Patricia McKee $^{5}$, Karilyn Schrankler ${ }^{5}$, Susan K. Raatz ${ }^{7}$, Leslie A. Lytle ${ }^{5}$, et_al. "Breakfast Frequency and Quality May Affect Glycemia and Appetite in Adults and Children”, J. Nutr. Vol/Issue: 141(1). Pp. 163-168, 2011.

[58] Sampson AE, Dixit S, Meyers AF, Houser RJ. "The nutritional impact of breakfast consumption on the diets of inner-city African-American elementary school children”, J Natl Med Assoc. Vol. 87. Pp. 195-202, 1995.

[59] Kral TV, Whiteford LM, Heo M, Faith MS. "Effects of eating breakfast compared with skipping breakfast on ratings of appetite and intake at subsequent meals in 8- to 10-y-old children”, Am J Clin Nutr. Vol/Issue: 93(2). Pp. 284-91, 2011. doi: 10.3945/ajen.110.000505. Epub 2010 Nov 17.

[60] Nicklas TA, Myers L, Reger C, Beech B, Berenson GS. "Impact of breakfast consumption on nutritional adequacy of the diets of young adults in Bogalusa, Louisiana: ethnic and gender contrasts”, J Am Diet Assoc. Vol/Issue: 98(12). Pp.1432-8, 1998. 
[61] Shaw, Mary E. Adolescent. "Breakfast Skipping: An Australian Study”, Adolescence, Vol/Issue: 33(132). Pp. 851861, 1998.

[62] Deshmukh-Taskar PR, Nicklas TA, O'Neil CE, Keast DR, Radcliffe JD, Cho S. “The relationship of breakfast skipping and type of breakfast consumption with nutrient intake and weight status in children and adolescents: the National Health and Nutrition Examination Survey 1999-2006”, J Am Diet Assoc. Vol/Issue: 110(6). Pp. 869-78, 2010. doi: 10.1016/j.jada.2010.03.023.

[63] Juan Sun, $\bigotimes^{1}$ He Yi, ${ }^{1}$ Zhiyue Liu, ${ }^{1}$ Yan Wu, ${ }^{1}$ Jiang Bian, ${ }^{1}$ Yanyan Wu, ${ }^{1}$ Yuki Eshita, ${ }^{2}$ Gaimei Li, ${ }^{3}$ Qing Zhang, ${ }^{1}$ and Ying Yang ${ }^{1}$."Factors associated with skipping breakfast among Inner Mongolia Medical students in China", BMC Public Health. Vol. 13. Pp. 42, 2013.

[64] Stockman NK, Schenkel TC, Brown JN, Duncan AM. "Comparison of energy and nutrient intakes among meals and snacks of adolescent males”, Prev Med, Vol. 41. Pp. 403-410, 2005.

[65] Berkey CS, Rockett HR, Gillman MW, Field AE, Colditz GA. "Longitudinal study of skipping breakfast and weight change in adolescents”, Int J Obes, Vol. 27. Pp. 1258-1266, 2003.

[66] Niemeier HM, Raynor HA, Lloyd-Richardson EE, Rogers ML, Wing RR. "Fast food consumption and breakfast skipping: predictors of weight gain from adolescence to adulthood in a nationally representative sample”, $J$ Adolesc Health. Vol/Issue: 39(6). Pp. 842-9, 2006. Epub 2006 Sep 27.

\section{BIOGRAPHIES OF AUTHORS}

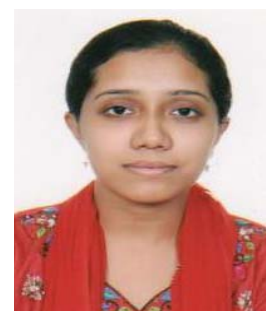

I am Shatabdi Goon. I have completed my bachelor degree with CGPA 4(out of scale 4) under the department of Nutrition and Food Engineering, Daffodil International University. I completed my secondary school certificate with GPA 5 and got gold medal for the achievement. I also got GPA 5 in my higher secondary school certificate. I got government scholarship in class five as well as in eight. I am very much interested in research. I have already published three of my research paper in 3 distinct international journals. I have also got chance participating in international conference on public health which had been held in Thailand. I am active member of Daffodil International University health club and doing different workshops and seminars regarding health and nutrition. I have taken the initiative to improve the micronutrient status of pregnant women and done some population base survey revealing the current status of malnutrition among pregnant women. I wish to work in nutrition sector aiming to improve the overall health status of Bangladeshi population.

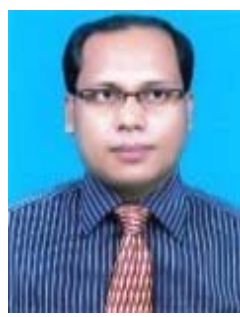

I am Md.Saiful Islam. I have completed my Master degree with CGPA 3.70 (out of scale 4) and also bachelor degree with first class first under the department of Applied nutrition \& food technology. Islamic University. I completed my secondary school certificate with GPA 3.69 I also got GPA 3.60 in my higher secondary school certificate. I got government Merit scholarship in Both Masters and Bachelor degree. I am very much interested in research. I have already published one of my research paper in 1 distinct international journals. I have also got chance participating in international conference on public health which had been held in Thailand. I am active member of Islamic University health club and doing different workshops and seminars regarding health and nutrition. I have taken the initiative to improve the micronutrient status of pregnant women and done some population base survey revealing the current status of malnutrition among pregnant women. I wish to work in nutrition sector aiming to improve the overall health status of Bangladeshi population. 